\title{
Innovative Business Models for Smart Cities - A Systematic
}

\author{
Nisha Shetty, Suresh Renukappa, Subashini Suresh
}

\begin{abstract}
- urban areas are the cars of development for a country. Savvy advances can help cope with the metropolis problems and enhance personal satisfaction, economic risk, and liveability for residents. urban regions income via a straightforward diagram of nice exercise solutions for turn out to be greater clever and from distinguishing most suitable arrangement suppliers. agencies that make metropolis areas more astute income thru getting step by step unmistakable to metropolis areas spherical the sector with their recently created or tested arrangements. innovative plans of movement help quicken the reception of savvy advances. exceptional subsidizing structures were utilized by city areas to create sensible town ventures. anyhow, it has been uncovered that the writing does not provide enough contemplations on these thoughts. This paper offers a recognise-a way to the concept of creative plans of motion and the appropriation of those in shrewd urban corporations. in addition the paper propels the comprehension at the advancing plans of movement and city acquisition tactics that might be utilized to quicken savvy town development. The paper attempts to cope with the inquiry: What are the problems regarded with the aid of institutions and sensible city areas to build up an powerful creative course of action? city areas have structured very plenty characterised techniques and are growing strategies for eager city. The paper cope with the problems and elements of an resourceful course of action for development of savvy city groups
\end{abstract}

Keywords- innovative plans of motion, eager urban communities, clever affiliation, stressful conditions, economic system.

\section{INTRODUCTION}

urban regions are liable for the financial development and personal delight. A degree of 38.nine billion dollars is classed to be spent on savvy city organizations [1]. urban corporations are the automobiles of development and count on a big task to perform quicker development, as a way to inevitably infer a essential alternate and a growing part of corporation and administrations components. Making arrangements for urbanization and better management of city regions is in this way now not just wonderful for the private delight for those living in our metropolis regions and cities, however further because it gives to a superior challenge surroundings. eager metropolis is an cheaper idea depending at the notion structures for residents and ventures. city communities need to be proficient, sensible, evenhanded and respectable [3]. eager urban groups are

Revised Manuscript Received on September 14, 2019.

Nisha Shetty, Department of Science and Engineering, University of Wolverhampton, Wolverhampton, United Kingdom, (Email: n.shetty@wlv.ac.uk)

Suresh Renukappa, Department of Science and Engineering, University of Wolverhampton, Wolverhampton, United Kingdom, (Email: suresh.renukappa@wlv.ac.uk)

Subashini Suresh, Department of Science and Engineering, University of Wolverhampton, Wolverhampton, United Kingdom, (Email: subashini.suresh@wlv.ac.uk) portrayed with mechanical improvements, technique trends and the management improvement [5]. IoT is the developing innovation nearly approximately eager urban agencies and is being set up for numerous obligations. utilization of IoT as an innovation to interface between the physical and digital international within the subject of waste administration should assist in noteworthy and requirements techniques [14]. As a check to urban manageability, savvy metropolis regions are selecting up the attention and force emphatically.

business structures are created to lessen costs and assets with the attention of offer. furthermore, they have got always been at the start of social improvement. Plans of movement have directed its manner via exceptional city organizations. Plan of movement can be characterized with the aid of 3 center segments of creating, conveying and catching an incentive within the financial, social and social styles of giant properly worth [13]. The significance of plans of movement in savvy city companies has grown colossally due to the quantity of companions engaged with the way. each help associated with the setting of excellent city groups related to a really worth proposition following contemporary-day or imaginitive plans of movement [13]. Plans of motion deliver an engineering configuration to eager urban regions and furnish the control with systems to satisfy client dreams. Plan for eager city companies and deliver the management methodologies to satisfy purchaser dreams. The idea of plans of movement is epitomized via 3 middle necessities of incentive, esteem creation and conveyance and certainly well worth capture.

The paper has an inclination to the examination hole in imaginative plans of motion for savvy city communities. It further investigations the writing and offers a working which means that of innovative direction of action. It examines the control and authoritative issues and advances with the essential additives of a creative route of motion for the improvement of eager city regions. The exam offers solutions to the exploration query: What are the issues regarded through associations and great metropolis communities to build up an effective creative path of motion?

\section{RESEARCH METHODOLOGY}

The paper follows a structured literature review. A database search on Scopus was conducted, followed by cross-referencing snowballing procedure to identify the relevant studies. As shown below: 


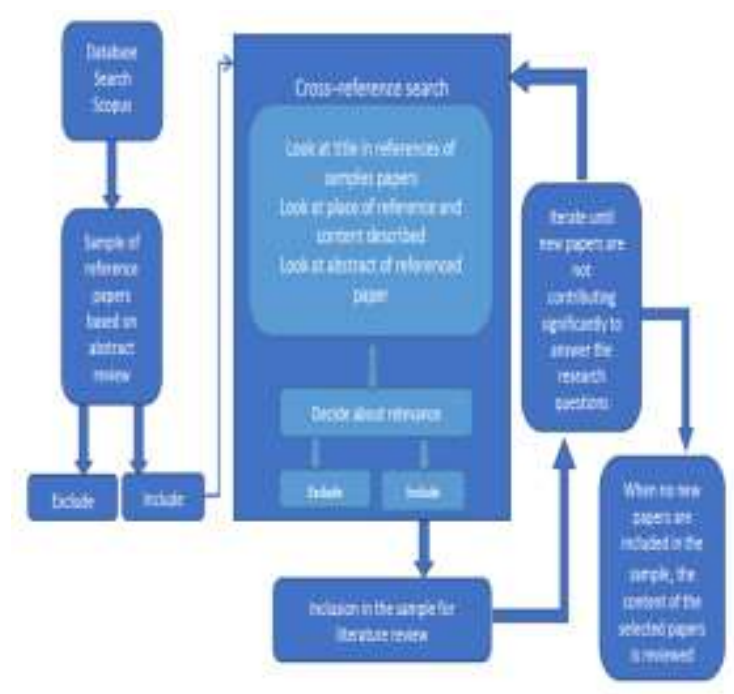

Fig 1. Developed illustration adapted on the literature review approach

Adopted from (Geissdoerfer et al., 2017)

As appeared over the hunt string "plan of action", "inventive plans of action" and " brilliant inovatif'dan'kota plan of action " was looked in 'Article Title' in the Scopus database. articles screened, unique looking into to get the underlying example for audit of the writing. Besides, incorporation and avoidance criteria are added to the picked article and important examples chose first. Pertinent crossreferences recognized in the underlying example and distribution in the reference and refered to in the content. Theoretical This production analyzed to check the pertinence of the examination. A similar procedure is proceeded with except if there is a further paper to add to explore. At long last, the paper tests acclimatized and organized to audit the writing.

\section{CHARACTERIZING THE INNOVATIVE BUSINESS MODEL}

A deliberate audit of the writing plan of action advancement is made to the meaning of the idea of creative plans of action. Different definitions are translated distinguished and blended into a working definition. advancement plan of action examined concerning higher benefits contrasted with item or procedure development [22]. Development at the degree of the plan of action will be an essential wherein motivators and salary can be credited so as to set up supportable arrangements [18]. In the work stream on the plan of action, plan of action advancement is a certain piece of the conceptualization [15]. plan of action development can be characterized dependent on various conditions. item advancement, administration development and change in the inventory network framing the premise to fit the bill for creative plans of action. Developing components of various plans of action give understanding into effective imaginative plans of action. The table underneath gives an alternate definition to creative plans of action.

Writing offers a definition close to the plan of action for non-public company or association. starting carried out definitions identified with innovative plans of movement for terrific town areas will be required. The definition gives know-how into the route of movement development and change

course of action or setup of the man or woman additives. course of action improvement has been designed on an essential concept comprising of 4 starting up, the trade of the direction of action, advanced plan of action, and the acquiring of the course of movement as portrayed beneath [15]

- start-up - no gift plans of action and new plans of movement made.

- business change version - the triumphing plan of action exists that is changed over into every other course of action.

- multiplied direction of movement - the prevailing path of movement remains installation and additional plans of motion made.

- the acquiring of enterprise model - An more plans of movement are distinguished, procured and coordinated.

An alternate definition gives running definitions to the solidification of revolutionary plans of action.

plan of action improvement can be characterized relying on the examination: as a portrayal and the utilization of latest plans of movement. advancement of a direction of motion clearly new to the distinction in more plan of action, the acquiring of latest plans of motion, or the change starting with one path of motion then onto the subsequent.

exchange can have an impact on the entire plan of action or an person or a aggregate of the motivation, esteem creation and convey, and seize esteem components, the connection many of the components, and tool esteem.

\section{INNOVATIVE BUSINESS MODELS FOR SMART CITIES -CONCEPTUALISATION OF ELEMENTS \& RESULTS}

Business model innovation describes the design process for giving birth to a fairly new business model on the market, advancement path of action depicts the structure approach to supply a direction of motion that is certainly new within the market, combined with the trade incentive and/or institution of stars of esteems and targets producing or verifying a realistic upper hand [14]. As characterised with the resource of [15], course of action advancement is "the conceptualization and usage of recent plans of motion. it is able to harm the development of a plan of action this is altogether new, superior into the course of action of the greater securing of new plans of motion, or the alternate starting with one course of action then onto the subsequent. trade may have an effect at the complete direction of movement or an man or woman or a combination of the inducement, esteem advent and give a element of large worth capture, the connection a few of the components, and machine esteem ". The above definitions are given to present an define of the importance of course of action development and the offer gave thru the incorporation of items, administrations and shop community improvement.

9 constructing squares of an powerful version to improve administrations commercial enterprise, purchaser interface, framework the board and budgetary elements of savvy urban 
communities created with the useful resource of [14]. the inducement gives a examine of administrations gave through the organization. in the consumer interface: goal customers portray the provide fragments, circulate channels assist to accomplice with customers and fabricate connections among the organisation and the client relationship. Spotlights on machine of the most considerable variables to be considered for the usage of effective course of motion. money associated viewpoints, for instance, the rate structure and earnings model outlining the monetary results of plans of movement. A path of movement want to be strategized with an emphasis on constructing long haul connections, authorities obligation, imaginative and prescient of factors to return again, adopt a elegant-primarily based technique, making hypothesis openings and appeal to populace to the use of innovation.

The different elements of the business model for smart cities analyses the relationship between them and discuss the manner of innovation on different elements that influence one another all the whilst. As dissected through way of Diaz-Diaz,

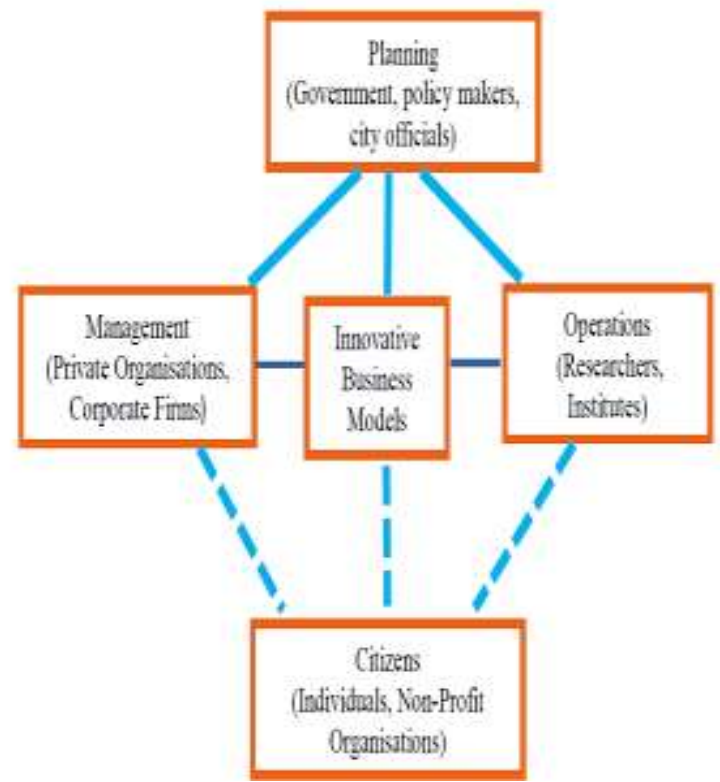

Figure 2: Demonstrating the business model functions for smart city development

the direction of action canvas can be utilized as a twofold benchmarking framework to consider diverse open administrations. An exam with the regular approach and creative philosophy has given an outcome social and herbal significances and advanced the board efficiencies. Plan of motion canvas is adjusted from [12].

the key components to be taken into consideration for modern plans of movement for brilliant metropolis groups are

- Key companions: who is probably accountable for the execution of the tasks

- Key sports: The process that should be pursued to direct the clever metropolis ventures.

- $\quad$ price Proposition: the center of the direction of action portrays what have to be completed to deliver and lure esteem. fortifying framework, incentive, center skills and companion

- client Segments: portrays the connection with customers.

- Key resources: Is associated with key physical activities and the fee shape.

- Channels: a way to arrive on the customers with wanted conveyed esteem.

- fee structure: The payments and spending prerequisite.

- sales Streams: blessings and the conveyance of benefits from the finished undertakings.

- Social and Environmental fees, Social and Environmental blessings: the extra hugeness of natural and social expenses which incorporates social and ecological benefits.

An underlying form planned Fig.2. received with reference from the direction of action canvas along four sizeable components enlarged from writing gives an expertise into the modern plans of motion for clever city areas.

An innovative course of movement specializing in the important thing additives to alternate, decorate reduce increment should assist inside the development of critical options for keen city corporations. The check faced is to make a network orientated manner to address development organic structures relying on feasible institutions the various fundamental companions from industrial organisation, research, method and resident gatherings and reap an association of close by, provincial technique levels and belongings. From the issue of view of keen metropolis groups, overseeing improvement on the degree of city development environments turns into an assignment of coping with the arrangement of property and advancing efficient interlinkages. fantastic metropolis development surroundings the executives expects to cope with the association of "development resources" made from the various offices and belongings, with the aid of making agencies among entertainers that administer those benefits, by means of way of encouraging records and statistics streams, and by way of using giving open access to assets made accessible to clients and engineers [20]. The alternate to extra astute metropolis agencies could require improvement in arranging, the executives, and duties. Coordinating the framework offers and advances the vital thing measurements and execution markers [21]. Detecting, statistics the board, investigation and showing and impacting consequences are the principle capacities defined for keen town path of motion advancement. city regions and locales around the world are using innovation development to enhance their arranging, the executives, and sports activities.

Arranging, the executives and responsibilities are the critical elements of development which center around the extensive barriers for savvy urban areas. first-class and prices of objects applied, protection and security are the troubles appeared at some stage in the detecting of city and its occupants. Overseeing one-of-a-kind data models, get to govern benchmarks and interoperability are kept up thru 
numerous places of work internal similar urban areas. metropolis physical games are comprehended through demonstrating and research that are a test the super city regions want to defeat with the great framework models. difficulties looked in the diploma of affecting end result, best framework control and human-town communication with individuals being the focal point of city's change.

\section{CONCLUSION}

This paper gives a much undertaking audit of the imaginative plan of action for smart urban corporations. The writing furnishes crude statistics and collectively with understanding of this facts and the that means of the important element idea of inventive path of motion and a properly-characterised discover hollow. creative path of motion is at a completely vicinity of knowledge segment of studies. The paper has an inclination to the exploration hole in innovative plans of action for savvy urban communities. It further explores the control and authoritative issues. A city reports problems inside the arranging, overseeing and obligations degree. Conquering those problems with a created plan of action gives a end result better communications with citizens. Detecting, facts overseeing, looking and impacting are the issues organized via the writing survey. The examination gives answers to the exploration question on the provokes seemed by means of outstanding urban areas to create imaginative plans of movement. The exploration query intends to create elucidating facts approximately the method institutions/governments revel in to transport into new innovative plans of action for savvy city areas development. Chiefs, foundation, commercial enterprise and residents offer the enlarged system to a plan of action hobby. development within the key additives of a course of movement provide a in addition research issue on sensible town resourceful plans of motion. The creators might additionally want to study and building up an concept prepare shape with understand to resourceful plans of motion for savvy urban areas..

\section{REFERENCES}

1. The network, CISCO generation news internet website, website: https://newsroom.Cisco.Com/public assertion content material?type $=$ webcontent $\&$ articleId $=1895705$, 2017

2. Addanki S.C, and Venkataraman H, (2017) 'Greening the economy: An audit of metropolis maintainability measures for growing new urban communities'. viable towns and Society 32, pp.1-eight.

3. Arora, R.U. (2018) monetary part development and remarkable town areas: The Indian case', Sustainable towns and Society forty two, pp. Fifty -fifty eight.

4. Singh, A. additionally, Jaiswal, k.okay. (2018) 'Simplicity of Doing commercial enterprise in India: A Affairs, 63(1), pp. 129-a hundred thirty five.

5. Rana, N.P., Luthra, S., Mangla, S.k., Islam, R., Roderick, S. also, Dwivedi, Y.ok. (2018) 'stumbling blocks to the development of clever cities in Indian Context', records systems Frontiers, , pp. 1-23. Srivatsa, P. (2015) 'Rustic urban Migration: disturbing the Equilibrium amongst clever cities and smart Villages', FIIB business review, 4(three), pp. 3-10. imaginative and prescient of Make in India', monetary

6. Mundoli, S., Unnikrishnan, H. moreover, Nagendra, H (2017) 'The "Supportable" in amazing metropolis areas: brushing off the importance of urban organic structures', choice, 40 four(2), pp. 103-one hundred twenty.

7. Bibri, S.E. additionally, Krogstie, J. (2017) smart supportable urban areas of things to return back: A wide interdisciplinary writing survey. Supportable towns and Society 31, pp.183-212.

8. . Gupta, Khushboo and hall, Ralph. (2017). The Indian factor of view of practical metropolis regions. 1-6. 10.1109/SCSP.2017.7973837.

9. . Gascó-Hernandez, Mila (2018). building a clever town: training from Barcelona. Correspondences of the ACM 61, pp. 50-57.

10. Venkatesham, Venkatigalla (2015). The problems and problems in urbanization of India. Paripex-Indian journal of research eleven, pp 277-278.

11. H. Chourai et. Al. "knowledge clever towns: An Integrative Framework", Proc. IEEE pc technological know-how Society, forty fifth Hawaii international conference on device Sciences, Hawaii, 2012, pp. 22892297.

12. Giffinger, Rudolph, Christian Fertner, Hans Kramar, Robert Kalasek, Natasa Pichler-Milanović and Evert Meijers (2007). keen cities: ranking of ecu MediumSized towns. Vienna, Austria: middle of nearby technological know-how, Vienna college of technology. Http://www.clever-cities.european/down load/smart cities_final_report.Pdf

13. Anthopoulos, L. furthermore, Fitsilis, P. (2015) information smart metropolis enterprise fashions: A contrast ACM.

14. Díaz-Díaz, R., Muñounces, L. furthermore, PérezGonzález, D. (2017) 'plan of action studies of open administrations running within the clever metropolis organic machine: the instance of SmartSantander', destiny era computer systems; future generation laptop systems, 76, pp. 198-214. Doi: 10.1016/j.destiny.2017.01.032.

15. Geissdoerfer, M., Vladimirova, D. furthermore, Evans, S (2018) 'sensible route of motion advancement: A survey', journal of cleanser manufacturing; journal of purifier production, 198, pp. 401-416. Doi 10.1016/j.Jclepro.2018.06.240

16. Thangavel C., Sudhaman P. (2018) A enterprise version for virtual offerings for clever cities in India. In: Mahmood Z. (eds) smart towns. computer Communications and Networks. Springer, pp 263-280

17. Bleus, H., Crutzen, N. furthermore, clever, C.I. (2018) business model and smart town, a writing audit.

18. Schiavone, F., Paolone, F. moreover, Mancini, D. (2018) business model improvement for metropolis smartization Elsevier Inc.

19. Khomsi, M. (2016) 'The clever metropolis ecosystem as an Innovation model: instructions from Montreal', era Innovation control review, 6(11), pp. 26-31. Doi: $10.22215 /$ timreview/1032

20. Schaffers H., Komninos N., Pallot M., Trousse B., Nilsson M., Oliveira A. (2011) clever cities and the destiny net: closer to Cooperation Frameworks for Open Innovation. In: Domingue J. Et al. (eds) The destiny internet. FIA 2011. talk Notes in laptop technological know-how, vol 6656. Springer, Berlin, Heidelberg

21. Naphade M, Banavar G, Harrison C, Paraszczak J, Morris R (2011), Smarter towns and Their Innovation challenges, IEEE laptop Society, pp 32-39 doi: report://C:/users/consumer/Downloads/05875937.Pdf 
22. Chesbrough, H. (2007), "Plan of motion development: it's far now not pretty much innovation any more", method and leadership, Vol. 35 No. 6, pp. 12-17. Https://doi.Org/10.1108/10878570710833714

\section{AUTHORS PROFILE}

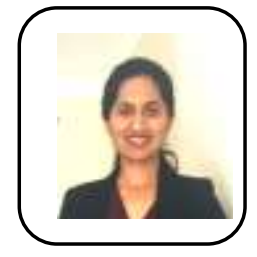

Nisha Shetty is a doctoral researcher in the Faculty of Science and Engineering at the University of Wolverhampton, United Kingdom. Her research explores the smart and sustainable cities development from an Indian context. She holds BEng (Hons) in Chemical Engineering from Visveswaraya Technology University and MSc in clean technology from the Newcastle University, United Kingdom. Also, she has worked as consultant in the field of sustainability management for 8 years. She has published four conference papers and one journal paper in the area of smart cities and business models innovation. Her research interests include: smart and sustainable cities, competitiveness, smart cities related policies, and development of innovative business models for smart cities.

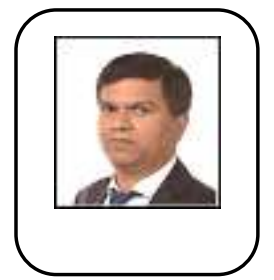

Dr Suresh Renukappa currently serves as a Senior Lecturer in the Faculty of Science and Engineering at the University of Wolverhampton. $\mathrm{He}$ holds a $\mathrm{PhD}$ in managing change and knowledge associated with sustainability initiatives for improved competitiveness. He has over 20 years of research, consultancy, project management and teaching experience in a wide range of business and management areas across industrial sectors in both developed and emerging economies. His research interests cover, but not limited to, sustainability strategies for competitive advantage; carbon reduction strategies; corporate social responsibility; smart cities development; leading change towards sustainability; knowledge management; public private partnerships; cloud computing; infrastructure asset management; and sustainable infrastructure investment and development. He has successfully executed more than 30 large projects and authored over 120 papers which have been published in journals, book chapters and conference proceedings.

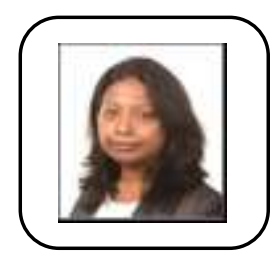

Dr Subashini Suresh has over 19 years of experience in research, teaching and practice in the area of Project Management and has worked in the area of Architecture, Engineering and Construction (AEC) sector in UK, USA, UAE, Nigeria, Ghana, Italy, Netherlands and India. Currently, she is a Reader of Construction Project Management at the School of Architecture and Built Environment, University of Wolverhampton. She holds a $\mathrm{PhD}$ in knowledge management. She received Rewarding Excellence Award for Innovation in Teaching and also for Blended Learning Tutor. She has published over 150 academic publications, which include 27 journal papers, 95 conference papers, four articles, eight book chapters, 15 reports and three books. Her key areas of interest are as follows: construction project management, knowledge management, building information modelling, health and safety, sustainability/green construction, emerging technologies, quality management, leadership in change management initiatives, organisational competitiveness, business process improvement, lean construction, risk management, and Six Sigma leadership. 